\title{
Mulheres no Contexto de Trabalho: Representações Sociais a partir da
}

\section{Orientação Sexual}

\author{
Natalia Fernandes Teixeira Alves* \\ Universidade de Fortaleza - Unifor, Fortaleza, CE, Brasil \\ ORCID: http://orcid.org/0000-0002-0722-1485 \\ Luciana Maria Maia** \\ Universidade de Fortaleza - Unifor, Fortaleza, CE, Brasil \\ ORCID: http://orcid.org/0000-0003-1491-5685 \\ Luiza Barbosa Porto Lima*** \\ Universidade de Fortaleza - Unifor, Fortaleza, CE, Brasil \\ ORCID: https://orcid.org/0000-0002-7192-7722 \\ Luana Elayne Cunha de Souza***** \\ Universidade de Fortaleza - Unifor, Fortaleza, CE, Brasil \\ ORCID: http://orcid.org/0000-0001-9425-9598 \\ Iara Andrade de Oliveira $* * * * * *$ \\ Universidade de Fortaleza - Unifor, Fortaleza, CE, Brasil \\ ORCID: https://orcid.org/0000-0003-0852-2826 \\ Ágatha Aila Amábili de Meneses Gomes******* \\ Universidade de Fortaleza - Unifor, Fortaleza, CE, Brasil \\ ORCID: http://orcid.org/0000-0002-7143-9876
}

\section{RESUMO}

O objetivo do presente trabalho foi identificar os elementos que compõem as representações sociais de estudantes universitários sobre a participação de mulheres no contexto de trabalho, tendo em vista a orientação sexual dessas mulheres. Para isso, 177 universitários responderam o Teste de Associação Livre de Palavras (TALP), com os termos indutores "mulheres no contexto de trabalho" e "lésbicas no contexto de trabalho". Os dados foram analisados por meio da Análise Prototípica, realizada pelo programa Iramuteq. Para as mulheres em geral, os resultados indicam o uso de palavras com conotações aparentemente positivas, mas que reforçam estereótipos de gênero, apontando funções socialmente definidas para mulheres. Para as lésbicas, os resultados centralizam o conteúdo no preconceito sofrido por essas enquanto membros da comunidade LGBT.

Palavras-chave: representações sociais, mulher, lésbica, preconceito, trabalho.

v. 20




\title{
Women in the Work Context: Social Representations Considering Sexual
}

\section{Orientation}

\begin{abstract}
The objective of the present study was to identify the elements that compose the social representations of university students about the participation of women in the work context, considering the sexual orientation of these women. To that end, 177 university students responded to the Free Word Association Test (TALP), with the terms "women in the work context" and "lesbians in the work context". The data were analyzed through the Prototypic Analysis, performed by the Iramuteq program. For women in general, the results indicate the use of words with apparent positive connotations, but reinforcing gender stereotypes, pointing to socially defined functions for women. For lesbians, the results center the content on the prejudice suffered by them as members of the LGBT community.
\end{abstract}

Keywords: Social representations, Woman, Lesbian, Prejudice, Work.

\section{Mujeres en el contexto laboral: representaciones sociales a partir de la}

\section{orientación sexual}

\section{RESUMEN}

El objetivo de esta investigación fue identificar los elementos que componen las representaciones sociales de estudiantes universitarios sobre la participación de las mujeres en el contexto laboral, considerando la orientación sexual de dichas mujeres. Con este fin, 177 estudiantes respondieron a la Prueba de Asociación Libre de Palabras, con los términos inductivos "mujeres en el contexto laboral" y "lesbianas en el contexto laboral". Los datos se analizaron mediante análisis prototípico, realizado por el programa Iramuteq. Para las mujeres en general, los resultados indican el uso de palabras con connotaciones aparentemente positivas, pero que refuerzan los estereotipos de género, señalando funciones socialmente definidas para las mujeres. Para las lesbianas, los resultados centran el contenido en los prejuicios que sufren como miembros de la comunidad LGBT.

Palabras clave: representaciones sociales, mujer, lesbiana, prejuicio, trabajo.

Até a década de 1960, o Código Civil Brasileiro assegurava aos homens o direito de proibir suas esposas de trabalhar fora de casa (Matos \& Borelli, 2012). Impulsionados pela ascensão do movimento feminista, o fim do século XX e início do XXI trouxeram significativas mudanças no campo social e político no que se refere à participação das mulheres na sociedade, com destaque para a conquista de importantes direitos. Esse 
movimento surgiu a partir da experiência de opressão e discriminação das mulheres e do desejo de relações mais igualitárias, livres de dominação e exclusão (Santos, Carvalho, Amaral, Borges, \& Mayorga, 2016).

Apesar das conquistas, a desigualdade de gênero ainda é uma realidade, sobretudo no contexto do trabalho (Proni \& Proni, 2018; Rosa \& Quirino, 2017). Segundo Rosa e Quirino (2017), embora as mulheres estejam inseridas no ambiente trabalhista, a estrutura e forma de ocupação dessas se mostram diferentes da ocupação masculina, uma vez que tendem a reproduzir nesse contexto tarefas de cuidado e organização que se aproximam às realizadas no âmbito domiciliar, enquanto os cargos gerenciais continuam sendo ocupados, em sua maioria, por homens.

Além da diferença de cargos, há diferença salarial entre os gêneros, uma vez que as mulheres recebem menos do que os homens, ocupando os mesmos cargos, ainda que tenham o grau de instrução equivalente ou maior (Leone \& Teixeira, 2013; Proni \& Proni, 2018). Segundo a Comissão Econômica para a América Latina e o Caribe (2016), embora a diferença salarial entre homens e mulheres tenha caído 12,1\% entre 1990 e 2014, o salário das mulheres continua sendo apenas $84 \%$ do que ganham os homens na América Latina.

O maior hiato salarial por sexo se verifica entre os trabalhadores autônomos, dos quais o rendimento feminino equivale a $65 \%$ do masculino (Leone \& Teixeira, 2013). A posição na ocupação mais equitativa é a dos empregados informais, em que as mulheres ganham o equivalente a $92 \%$ da renda dos homens. Ademais, no final de 2015, as mulheres ganhavam em média 16,1\% menos do que os homens (Proni \& Proni, 2018). Essa disparidade salarial, de acordo com o Fórum Econômico Mundial, só será superada em 217 anos (World Economic Forum, 2017).

Entre outros obstáculos que as mulheres enfrentam no mundo do trabalho está o assédio, podendo ser sexual ou moral (Gregus, Rummel, Rankin, \& Levant, 2014). O assédio sexual refere-se à imposição de favores sexuais não desejados, nem consentidos, prevalecendo-se da relação de superioridade no trabalho (Freitas, 2001; Garbin \& Fischer, 2012). O assédio moral caracteriza-se por condutas abusivas e humilhantes nos relacionamentos interpessoais (Nunes \& Tolfo, 2015).

De acordo com Louise Fitzgerald (1993), uma a cada duas mulheres nos Estados Unidos serão submetidas a alguma forma de assédio durante a sua vida acadêmica ou profissional. No Brasil, esta também é uma problemática muito comum. Isto pode ser visto em uma campanha sobre assédio sexual realizada pelo projeto Think Olga, em 2013, que entrevistou mais de 8 mil mulheres dos mais diversos estados do país e concluiu que $33 \%$ das 
mulheres afirmaram ser incomodadas no trabalho pelo superior (33\%), colega (21\%), cliente (14\%) e funcionário (9\%).

Algumas pesquisas indicam que essa disparidade entre homens e mulheres no contexto de trabalho pode ser agravada no caso das mulheres lésbicas, que podem sofrer discriminação também em decorrência da orientação sexual. A Organização Internacional do Trabalho estimou que trabalhadores/as LGBT encontram bastante dificuldade no acesso ao emprego no Brasil (Jordão, 2011). Uma pesquisa realizada em oito países revelou que o Brasil é o país cujo maior número de pessoas LGBT relatou sofrer piadas e brincadeiras preconceituosas no trabalho, em comparação com Índia, França, Estados Unidos, Reino Unido, Itália, México e Alemanha (Salino, Covolan, Pereira, \& Signorelli, 2018).

Estudos indicam que a particularidade do preconceito sofrido por lésbicas decorre tanto de questões sexistas, que beneficiam os homens, como questões heteronormativas, que impõem a heterossexualidade como norma hegemônica. Tem-se, dessa forma, um acúmulo de preconceitos que as coloca em uma situação de dupla vulnerabilidade, resultado da intersecção entre sexismo e lesbofobia (Neto \& Bichalho, 2017; Salino, 2017).

Os estudos de Peplau e Fingerhut (2004) e Torma (2013), por sua vez, indicam uma perspectiva contrária, mostrando que lésbicas sentem a necessidade de se firmar financeiramente mais cedo, ao mesmo tempo em que não dedicam tanto tempo para atividades tradicionalmente atribuídas à mulher, como o cuidado com casa e filhos. Esse comportamento levaria lésbicas a se dedicarem mais aos estudos e a carreira, colocando-a em posição de vantagem em relação às mulheres heterossexuais, que se sentem mais cobradas a atender tais expectativas de gênero. E, mesmo quando apresentam uma relação estável, as tarefas domésticas são mais bem divididas e administradas entre os pares em comparação a um casal heterossexual.

A partir desse breve panorama sobre a situação de desigualdade que as mulheres vivenciam no contexto de trabalho, parece evidente que não é possível falar de uma única forma de discriminação contra todas as mulheres. Como já apresentado, não só o gênero, mas também a orientação sexual, funcionam como importantes demarcadores sociais nas relações que os indivíduos estabelecem em sociedade. Neste sentido, apresentam-se a seguir duas formas de preconceito contra mulheres, seja em função do sexo (o sexismo) ou em função de sua orientação sexual (a lesbofobia). 
Natalia Fernandes Teixeira Alves, Luciana Maria Maia, Luiza Barbosa Porto Lima, Luana Elayne Cunha de Souza, Iara Andrade de Oliveira, Ágatha Aila Amábili de Meneses Gomes

\section{Sexismo}

Independente da orientação sexual, as mulheres podem ser vítimas do sexismo, que é definido como uma forma de preconceito baseada no sexo, resultado de prescrições e descrições acerca do papel feminino na sociedade (Glick \& Fiske, 1996). Devido ao teor ambíguo que o sexismo pode assumir, o fenômeno é estudado a partir de sua ambivalência, dividindo-o em dois polos: hostil e benevolente. O sexismo hostil é mais flagrante e explicitamente pejorativo, deixando claro que a mulher está sendo desfavorecida, ao passo que o sexismo benevolente é expresso por meio de atitudes aparentemente positivas, de forma que a mulher parece estar sendo favorecida, mas continua engessando-a em papéis específicos (Glick \& Fiske, 1996).

Esses dois polos são compostos por três elementos: o paternalismo, a diferenciação de gênero e a heterossexualidade, expressos de forma diferente para cada um deles. Por ser composto por afetos negativos, os elementos constituintes do sexismo hostil, adotam uma conotação mais ofensiva. Aqui o paternalismo é dominante e marcado por uma necessidade de controlar a mulher, reservando a ela um tratamento infantilizado; a diferenciação de gênero é competitiva, buscando distinguir, exacerbar e generalizar a diferença entre os gêneros, de forma que o homem seja colocado como sendo superior; e a heterossexualidade é hostil, assim, existe uma tendência de direcionar esses sentimentos negativos para a mulher, por usarem a atração sexual como forma de manipulação dos homens, enxergando-a como adversária (Barreto \& Ellemeres, 2005; Glick \& Fiske, 1996; Kilianski \& Rudman, 1998).

O sexismo benevolente, por sua vez, assume tons aparentemente positivos. Sob a forma de paternalismo, adquire uma faceta protetora, a exemplo da crença de que as mulheres devem ser protegidas pelos homens. Ao passo que a diferenciação de gênero assume um viés complementar, no qual as mulheres seriam dotadas de qualidades que poucos homens possuem, sendo em sua maioria, domésticas. Já a heterossexualidade é explorada através da intimidade, como por exemplo, por meio da crença de que as mulheres preenchem as necessidades românticas dos homens (Barreto \& Ellemeres, 2005; Glick \& Fiske, 1996; Kilianski \& Rudman, 1998).

Portanto, a teoria do sexismo ambivalente sugere que, tanto as atitudes negativas quanto as positivas, são formas de expressar uma percepção de incompetência ou inferioridade feminina (Glick \& Fiske, 2011). Embora expressas de formas diferentes, as duas vertentes do sexismo se complementam e sustentam a desigualdade de gênero, considerando que, na sociedade moderna, o preconceito contra a mulher se dá através de atitudes e papéis 
de gênero como formas atualizadas de crenças sexistas (Barreto \& Ellemers, 2005; Glick \& Fiske, 1996; Glick \& Fiske, 2011).

\section{Lesbofobia}

No presente trabalho, utiliza-se o termo lesbofobia para se referir às experiências de discriminação e preconceito que mulheres lésbicas sofrem. Diferentemente das mulheres heterossexuais, que sofrem preconceito por seu gênero e dos homens gays que sofrem preconceito por sua orientação sexual, mulheres lésbicas sofrem uma acumulação de preconceitos por fazerem parte de duas minorias sociais (mulheres e homossexuais) (Neto \& Bichalho, 2017; Salino, 2017).

O conceito da heterossexualidade compulsória ajuda essa discussão ao explicar o processo em que a norma heterossexual impõe um padrão destinado a garantir o privilégio do homem heterossexual em todos os âmbitos da sociedade. Deste modo, a partir da heterossexualidade compulsória, pressupõe-se que todas as mulheres são, obrigatoriamente, heterossexuais. Mulheres lésbicas ferem o princípio da heterossexualidade compulsória e são, portanto, discriminadas e invisibilizadas por isso (Rich, 2010). A este respeito, o Brasil é um dos países que mais mata pessoas LGBTs no mundo. Dos 445 assassinatos de pessoas LGBTs no Brasil no ano de 2017, 21\% eram mulheres lésbicas. Tais crimes foram perpetrados, muitas vezes, por ex-companheiros ou familiares inconformados com a união homoafetiva, estando seus homicídios ligados diretamente à discriminação devido à orientação sexual (Grupo Gay da Bahia, 2018).

Ainda para fomentar a discussão, a lesbofobia pode ser definida como o medo que as mulheres têm de amar outras mulheres, assim como o medo que os homens (incluindo os gays) têm das mulheres não os amar. Quando mulheres lésbicas decidem ter um relacionamento, enviam uma mensagem de resistência à sociedade, contradizendo o que o patriarcado exige, indo contra o sexismo, não se curvando assim à suposta superioridade masculina na qual a heterossexualidade compulsória opera (Petersen, 1994).

Ademais, a discriminação sofrida por lésbicas pode vir diretamente de outras mulheres heterossexuais. Em se tratando do grupo social de seu gênero, mulheres heterossexuais podem vir a se distanciar socialmente de mulheres lésbicas por temerem sofrer, por tabela, com o estigma associado a estas. A expressão de opiniões diferentes das que o indivíduo verdadeiramente defende para se distanciar de um grupo, neste caso, mulheres lésbicas, pode ser considerada como uma expressão sutil de preconceito (Swim, Ferguson, \& Hyers, 1999). 


\section{Representações Sociais}

Tendo em vista que os diferentes processos que envolvem as mulheres passam pela compreensão da sociedade e por teorias do senso comum, que podem ser analisadas como formas de representações que se desenvolvem nas dinâmicas entre homens e mulheres, heterossexuais e homossexuais, o aporte teórico aqui utilizado é proveniente do campo de estudos das Representações Sociais (Moscovici, 2017), de forma específica da Teoria Estrutural das Representações Sociais, que permite compreender a estrutura das representações (Abric, 2001).

Essa teoria analisa as Representações Sociais (RS) a partir de seu Núcleo Central (NC) e de seus Elementos Periféricos (EPs). O NC possui uma função geradora e organizadora, sendo composto pelos principais elementos que formam a representação, que são resistentes a mudanças, pouco sensíveis ao contexto imediato e ligados à história do grupo (Abric, 2001; Sá, 1996; Wachelke \& Wolter, 2011). Os EPs representam a parte mais acessível da RS e constituem o elo entre o núcleo e às práticas. Esses elementos estão mais ligados ao contexto imediato, sendo mais flexíveis e podendo conter mais informações novas. Além disso, funcionam como um sistema de defesa para as representações, pois, quando ocorrem mudanças no contexto, a representação não se modifica por completo (Sá, 1996; Wachelke \& Wolter, 2011).

Os EPs são subdivididos em Primeira Periferia (PP), Segunda Periferia (SP) e Zona de Contraste (ZC). Na PP localizam-se representações individuais, mas que podem ter elementos considerados centrais. Na SP podem existir elementos que fazem parte de realidades mais específicas. Na ZC estão elementos que podem se opor ao NC, podendo até mesmo modificálo no futuro; ou elementos que ainda não passaram por um maior consenso da população; e, a depender da representação, podem conter elementos que continuam os significados da PP (Wachelke \& Wolter, 2011). Diante do exposto, este trabalho tem como objetivo geral identificar os elementos que compõem as representações sociais de estudantes universitários sobre a participação de mulheres no contexto de trabalho, tendo em vista a orientação sexual dessas mulheres. 


\section{Método}

\section{Participantes}

Participaram 177 estudantes oriundos de cursos de graduação, especificamente dos cursos de Administração, Psicologia, Medicina e Direito, de uma instituição de ensino superior privada da cidade de Fortaleza - CE, com idades variando entre 18 e 59 anos $(\mathrm{M}=$ $22,45$, DP $=6,66)$. Do total, a maioria era heterossexual $(94,8 \%)$ e do sexo feminino $(55,1 \%)$. Dentre as participantes mulheres, a maioria também era heterossexual $(95,9 \%)$.

\section{Instrumento}

Para a coleta dos dados, utilizou-se o Teste de Associação Livre de Palavras (TALP), com o objetivo de identificar o campo semântico relativo às concepções sobre a participação das mulheres no contexto de trabalho. Os termos indutores utilizados foram "mulheres no contexto de trabalho" e "lésbicas no contexto de trabalho". Solicitou-se que o participante escrevesse as três primeiras palavras que surgissem em sua cabeça. Ressalta-se que, no primeiro estímulo, embora o termo indutor tenha sido somente "mulheres", não especificando a orientação sexual, supôs-se que os participantes associaram a imagem ao padrão dominante, isto é, mulheres brancas e heterossexuais. Os participantes também responderam a um questionário sociodemográfico contendo perguntas sobre idade, gênero e orientação sexual.

\section{Coleta de Dados e Procedimentos Éticos}

Os participantes foram abordados em sala de aula e convidados a participar voluntariamente da pesquisa. Aqueles que aceitaram, preencheram o Termo de Consentimento Livre e Esclarecido (TCLE) e em seguida responderam o instrumento de pesquisa no mesmo local em que foram abordados. Ressalta-se que a coleta foi realizada após autorização institucional e aprovação do projeto pelo comitê de ética da Universidade de Fortaleza, tendo em vista atender às Resoluções 466/2012 e 510/2016 do Conselho Nacional de Saúde. O número do parecer é 1.525.237, referente ao projeto "O que pensam os universitários sobre a participação e vivências de minorias sociais no contexto do trabalho", do qual parte o presente artigo. 


\section{Análise dos Dados}

Após essa coleta, foi criado um banco de dados. As informações sociodemográficas foram analisadas através da estatística descritiva no software SPSS. Já as palavras mencionadas passaram por um processo de lematização e foram contabilizadas por meio do programa Iramuteq - Interface de $R$ pour les Analyses Multidimensionnelles de Textes et de Questionnaires (Ratinaud, 2009). O Iramuteq é um software que facilita análise de dados textuais, por meio de recursos estatísticos e gráficos. Utilizou-se a função matriz do programa e, para ter acesso a dados relativos às representações sociais, fez-se inicialmente a Análise de Frequências Múltiplas, partindo das frequências relativas e absolutas obtidas na primeira análise. Foram realizadas as Análises Prototípicas, técnica comumente utilizada para a caracterização da representação social de maneira estrutural. Esse processo foi feito individualmente para cada um dos estímulos indutores (Camargo \& Justo, 2013; Wachelke \& Wolter, 2011).

A Análise Prototípica baseia-se no cálculo da frequência e ordem das palavras evocadas, gerando um quadro com quatro quadrantes, como exposto na Figura 1. Os quadrantes são divididos em: NC, que contém palavras que foram prontamente evocadas e com maior frequência; e elementos periféricos, que incluem a PP, composta por palavras com alta frequência, porém tardiamente evocados; a SP, contemplando palavras tardiamente evocadas e com baixa frequência; e a ZC, composta por palavras com baixa frequência, porém mais prontamente evocadas (Camargo \& Justo, 2013; Wachelke \& Wolter, 2011).

\begin{tabular}{|c|c|c|c|}
\hline \multirow{4}{*}{ 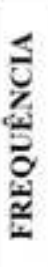 } & \multirow{3}{*}{$\stackrel{g}{\tilde{z}}$} & \multicolumn{2}{|c|}{ ORDEM DE EVOCACĀO } \\
\hline & & Baixa & Alta \\
\hline & & Núcleo Central (NC) & Primeira Periferia (PP) \\
\hline & $\frac{\mathscr{g}}{\mathrm{m}}$ & Zona de Contraste ( $\mathrm{ZC}$ ) & Segunda Periferia (SP) \\
\hline
\end{tabular}

Figura 1. Análise Prototípica

\section{Resultados e Discussão}

Considerando as palavras apresentadas no TALP, foram obtidas 189 evocações diferentes sobre mulheres e 213 sobre lésbicas. Para a análise prototípica, foi utilizada como 
corte a frequência mínima de 6 para a inclusão na análise dos resultados de mulheres e de 5 para lésbicas, correspondendo, respectivamente, a 3,39\% e 2,89\% no total de linhas.

\section{Tabela 1}

\section{Análise Prototípica sobre Mulheres}

\begin{tabular}{|c|c|c|c|c|c|c|c|}
\hline \multicolumn{2}{|l|}{ Categoria } & Palavra & Freq. & Ordem & Palavra & Freq. & Ordem \\
\hline \multirow{18}{*}{ 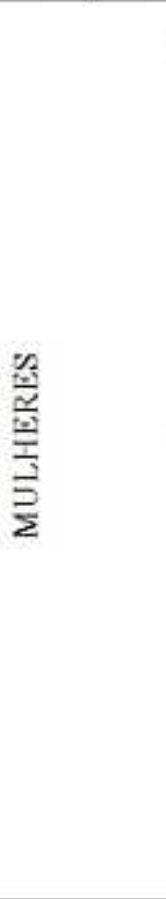 } & & \multicolumn{3}{|c|}{ Ordem $\leq 1.94$} & \multicolumn{3}{|c|}{ Ordem $>1.94$} \\
\hline & & Desigualdade & 33 & 1.8 & Competente & 26 & 2.1 \\
\hline & & Igualdade & 26 & 1.9 & Conquista & 14 & 2.2 \\
\hline & $F>$ & Esforçada & 20 & 1.9 & & & \\
\hline & 12.26 & & & & & & \\
\hline & & Luta & 18 & 1.8 & & & \\
\hline & & Salário & 16 & 1.9 & & & \\
\hline & & Organizada & 15 & 1.6 & & & \\
\hline & & Preconceito & 14 & 1.9 & & & \\
\hline & & Direito & 9 & 1.6 & Independente & 10 & 2.3 \\
\hline & & Guerreira & 9 & 1.6 & Injustiça & 7 & 2.0 \\
\hline & & Empoderamento & 8 & 1.8 & Assédio & 7 & 2.4 \\
\hline & $\mathrm{F} \leq$ & Determinada & 8 & 1.8 & Inteligente & 6 & 2.0 \\
\hline & & Mãe & 6 & 1.0 & Liberdade & 6 & 2.0 \\
\hline & & & & & Dedicada & 6 & 2.0 \\
\hline & & & & & Dificuldade & 6 & 2.0 \\
\hline & & & & & Responsável & 6 & 2.3 \\
\hline & & & & & Desafio & 6 & 2.3 \\
\hline
\end{tabular}

Como pode ser acompanhado na Tabela 1, em relação às mulheres, aparecem no NC e na PP palavras que sugerem a luta pela igualdade e a conquista de espaço da mulher no contexto de trabalho ("luta", "conquista", "salário", "igualdade”), bem como determinadas competências organizacionais ("organizada", "esforçada", "competente"). Apesar disso, as palavras "preconceito" e "desigualdade" parecem indicar o reconhecimento da manutenção desses fenômenos.

Essas evocações sugerem que, embora as mulheres, por meio de ativismo e esforços próprios, sejam reconhecidas como tendo de fato conquistado mais espaço e melhorias na condição de trabalho (Amaral, 2012), a luta ainda se faz necessária e constituinte do lugar da mulher dentro dessa conjuntura. Exemplo disso consiste na dificuldade de acesso à posição de liderança ou poder em diversas organizações, bem como a desigualdade de salários entre homens e mulheres (Nogueira, 2006).

Ainda no primeiro quadrante, têm-se as palavras "esforçada" e "organizada", que estão imbuídas de conotações aparentemente positivas, mas que reforçam os estereótipos de gênero. Estas evocações parecem sugerir uma expressão de sexismo benevolente, por meio do 
conjunto de atitudes que situa a mulher de acordo com o estereótipo de gênero e a restringe a papéis que são aparentemente positivos e tipicamente caracterizados como pró-sociais (Glick \& Fiske, 1996). Parece existir uma tendência à ideologia que busca caracterizar as mulheres como menos capacitadas para determinados tipos de atividade, como cargos de liderança (Belo \& Camino, 2012; Peplau \& Fingerhut, 2004; Verniers \& Vala, 2018). Isso remete às atividades laborais que historicamente foram e são atribuídas às mulheres, como por exemplo, no setor de serviço de trabalhos burocráticos, em que se buscavam mulheres ágeis e submissas; e no contexto industrial, cujos trabalhos exigiam cuidado, rapidez e concentração (Matos \& Borelli, 2012).

$\mathrm{Na}$ SP, as palavras ainda continuam seguindo o mesmo conteúdo dos significados supracitados, que remetem a competências organizacionais e dificuldades de inserção no contexto trabalhista. No entanto, destaca-se a palavra "assédio", tendo em vista que nesse quadrante podem ser encontradas palavras destinadas a contextos específicos (Wachelke \& Wolter, 2011). Ressalta-se que o assédio é uma realidade vivenciada por mulheres em diferentes contextos, como o ambiente de trabalho, e mantem-se, mesmo que seja uma conduta considerada crime (Garbin \& Fischer, 2012).

A ZC contém elementos que se opõem aos demais quadrantes, podendo futuramente compor a PP ou NC (Wachelke \& Wolter, 2011). Na presente pesquisa, a ZC permanece reunindo termos que se aproximam da discussão proposta para os quadrantes anteriores (“direito", "guerreira", "empoderamento" e "determinada"). Destaca-se "empoderamento" como, provavelmente, sendo importante para alguns indivíduos, mas que ainda não faz parte de um consenso de uso. Esse termo compreende duas esferas: individual, que envolve ressignificações nos processos cognitivos, voltados para o desenvolvimento de maior autonomia; e coletiva, que engloba mudanças em uma perspectiva ampla, alterando o contexto, por exemplo, através de uma educação não sexista e inserção em cargos de poder (Cortez \& Souza, 2008; León, 2001).

Contrariando essa perspectiva, tem-se a palavra "mãe", que aparece como uma forma de oposição ao NC, tendo em vista que ainda se relaciona a um papel social que a mulher pode exercer fora do contexto de trabalho. Pela centralidade desse papel, mesmo quando o estímulo "mulher no contexto de trabalho" deveria tirá-la da esfera privada, essa palavra foi evocada. Isso pode ser relacionado à função de cuidados domésticos ainda atribuídos como obrigatórios somente às mulheres, a chamada divisão sexual do trabalho (Matos \& Borelli, 2012; Reis \& Freitas, 2016). Assim, embora as principais palavras que foram evocadas nesta pesquisa sugiram uma aquisição de espaço da mulher nesse contexto, ainda há atribuições, 
obrigações e funções socialmente definidas para homens e mulheres, que permanecem nas concepções culturais (Belo \& Camino, 2012).

\section{Tabela 2}

\begin{tabular}{|c|c|c|c|c|c|c|c|}
\hline Categori & & Palavra & Freq. & Ordem & Palavra & Freq. & Ordem \\
\hline \multirow{14}{*}{$\frac{2}{\frac{5}{3}}$} & & \multicolumn{3}{|c|}{ Ordem $\leq 1.74$} & \multicolumn{3}{|c|}{ Ordem $>1.74$} \\
\hline & & Preconceito & 67 & 1.4 & Discriminação & 14 & 1.9 \\
\hline & & Igualdade & 26 & 1.6 & & & \\
\hline & $F>13.73$ & Normal & 17 & 1.3 & & & \\
\hline & & Homofobia & 11 & 1.5 & Desigualdade & 13 & 1.2 \\
\hline & & & & & Respeito & 10 & 1.9 \\
\hline & & & & & Luta & 9 & 2.3 \\
\hline & $F \leq 13,73$ & & & & Competência & 7 & 2.0 \\
\hline & & & & & Exclusão & 6 & 2.2 \\
\hline & & & & & Dificuldade & 6 & 2.3 \\
\hline & & & & & Injustiça & 5 & 2.2 \\
\hline & & & & & Feminismo & 5 & 2.0 \\
\hline & & & & & Aceitação & 5 & 2.0 \\
\hline & & & & & Oportunidade & 5 & 2.6 \\
\hline
\end{tabular}

Nos resultados relativos às mulheres lésbicas, observados na Tabela 2, predominam palavras que remetem ao preconceito e à discriminação sofrida por esse grupo. Aparecem no $\mathrm{NC}$ e na PP termos que reconhecem as experiências de discriminação e preconceito em relação à mulher, de modo geral ("preconceito"; “discriminação"). Entretanto, as palavras "igualdade" e "normal" indicam um aspecto aparentemente positivo, mas que podem estar sendo utilizadas como reforçadores da desigualdade, encobertas por um preconceito velado (Lima, 2003). Assim, o termo "normal", por exemplo, parece indicar uma neutralização da diferença, mas também pode atuar como uma negação desse processo.

$\mathrm{Na} \mathrm{SP}$, os termos também parecem referir-se à necessidade de inclusão e aceitação dessas mulheres nos contextos de trabalho (“desigualdade", "injustiça”, "respeito", "luta”). Porém, somente nesse momento aparece uma palavra que caracteriza o grupo de maneira positiva e que não se relaciona com o contexto de exclusão social do grupo ("competência"). Essa palavra parece remeter às representações associadas à mulher lésbica, que as aproximam 
dos estereótipos de gênero masculino e as distanciam dos de gênero feminino. Na divisão sexual do trabalho (Hirata, 2005), essas representações colocam a mulher lésbica em uma posição superior à mulher heterossexual, uma vez que, no imaginário social, essas mulheres dedicam-se mais à carreira e aos estudos do que aos filhos e às atividades domésticas (Peplau \& Fingerhut, 2004; Torma, 2013). No entanto, vale ressaltar que na SP aparecem elementos que fazem parte de realidades de participantes mais específicos, não sendo as principais representações sociais de um grupo.

Uma palavra que também chama atenção nesse quadrante é "feminismo", que não foi mencionado para o grupo de mulheres em geral. O surgimento desse termo apenas para as lésbicas parece remeter à associação do movimento feminista com estereótipos dirigidos às mulheres lésbicas, como a ideia de que feministas, assim como as lésbicas, não gostam de homens (Soares \& Costa, 2011). Considerando que a maioria da amostra foi formada por mulheres heterossexuais, é possível que tenham atribuído a palavra "feminismo" ao grupo de lésbicas, especificamente, para que não sejam associadas ao grupo minoritário em questão, buscando distanciar-se do estigma ligado ao mesmo.

Acerca disso, Swim, Ferguson e Hyers (1999) indicam que as pessoas podem buscar se diferenciar das mulheres lésbicas, alterando as expressões de suas opiniões, especialmente se tiverem atitudes negativas sobre essas. Nesse sentido, desejando não serem associadas ao estigma destinado a grupos marginalizados, é possível que se afastem destes indivíduos, mesmo que tenham semelhanças. Ademais, Garnets (1996) aponta que mulheres heterossexuais podem evitar se declarar como feministas, confrontar declarações homofóbicas ou estabelecer relações de amizade com mulheres lésbicas por temerem ser taxadas como lésbicas.

Já na ZC, surge apenas a palavra "homofobia", que remete à ideia de preconceito, mais especificamente em relação à orientação sexual. Ao aparecer nessa zona, provavelmente essa palavra surge como tendência futura de centralidade nas representações acerca dessa minoria, visto que é uma palavra que está sendo mais utilizada como maneira de especificar o preconceito contra homossexuais.

Após as análises dos resultados de forma separada, buscou-se fazer uma análise comparativa entre as duas estruturas de representações. Ressalta-se que a palavra "mãe" não foi evocada para lésbicas, ratificando a ideia do senso comum de não reconhecer uma mulher lésbica como mãe (Kite \& Deaux, 1987), mesmo que um percentual considerável dessas tenha filhos (Morris, Balsam, \& Rothblum, 2002). Segundo Dunne (1997), esses estereótipos podem, por vezes, funcionar como vantagem para a mulher lésbica, que passa a ser vista pelo 
chefe como uma funcionária "séria", menos provável de deixar o trabalho para casar ou ter filhos.

Outra palavra que compôs especificamente a representação das mulheres em geral foi “assédio". Para Dunne (1997), lésbicas assumidas tendem a sofrer em contextos de trabalho majoritariamente masculinos, menos assédio sexual de colegas de trabalho homens do que as mulheres heterossexuais. Em contraponto, as mulheres lésbicas sofrem enquanto membros da comunidade LGBT, o que pode ser evidenciado pela centralização das evocações no preconceito sofrido por sua orientação sexual. Dessa forma, parece que, na percepção dos universitários desse estudo, a experiência de lésbicas no contexto de trabalho está perpassada principalmente pelas questões em torno da orientação sexual em detrimento das de gênero.

Por fim, ressalta-se que existiu uma menor variabilidade de palavras para designar o grupo de lésbicas, de modo que aparecem palavras semelhantes às do grupo das mulheres, entretanto, com a frequência mais elevada devido à pouca variação. Essa situação fez, inclusive, com que o valor mínimo de frequência na Análise Prototípica entre os grupos fosse diferente, sendo menor para lésbicas, com o objetivo de apresentar um percentual de palavras mais representativo em relação ao total de linhas. Essa menor variabilidade aparenta indicar uma homogeneização do grupo de lésbicas, constituído a partir de estereótipos, o que pode ser explicado pelo maior número dos respondentes não serem pertencentes a esse grupo, uma vez que a maioria dos participantes era heterossexual. O processo de categorização social pode explicar esse resultado, tendo em vista que os membros do grupo que os respondentes não fazem parte, exogrupo, são vistos como mais parecidos entre si do que realmente são, ou seja, como sendo um grupo homogêneo. Tal fenômeno contribui para a formação de uma imagem estereotipada das pessoas que pertencem ao grupo minoritário, lésbicas (Tajfel, 1982).

\section{Considerações Finais}

Nessa pesquisa, observou-se que embora as mulheres tenham alcançado conquistas no mercado de trabalho, as relações de poder masculino ainda se evidenciam nas representações sociais sobre esse grupo dentro do contexto de trabalho. Isso pode ser percebido pela evocação de palavras negativas, que deixam clara essa situação de desigualdade e a necessidade de mudanças, mas também, por meio de palavras aparentemente positivas, que reforçam estereótipos de gênero e, consequentemente, enquadram as mulheres dentro de profissões específicas, as quais remetem a papéis de gênero tradicionais. 
No entanto, também foram evocadas palavras que sugerem relação com as conquistas dos movimentos sociais feministas e LGBT e com a promulgação de leis relacionadas à defesa de direitos dos grupos de mulheres, tanto heterossexuais quanto lésbicas, que contribuíram com avanços em relação à participação da mulher na sociedade. Dessa maneira, observam-se resultados que podem ser relacionados ao maior protagonismo das mulheres no mercado de trabalho que, mesmo que ainda não seja o ideal, apresenta avanços em relação ao lugar que historicamente é destinado à mulher nesse contexto.

Quando a orientação sexual da mulher é levada em consideração, notaram-se modificações nas representações sociais. As palavras evocadas sobre lésbicas no contexto de trabalho apresentaram uma centralização na exclusão sofrida devido à orientação sexual. Nessa situação, há uma diminuição de palavras positivas e a predominância de palavras que remetem ao processo de luta e preconceito vivenciado.

Além disso, pode-se observar que, para as lésbicas, não apareceu a palavra "mãe", o que sugere uma concepção errônea vinculada ao estereótipo de que apenas mulheres heterossexuais podem ter filhos. A palavra "assédio" também não surgiu nessa análise, o que parece remeter a uma percepção estereotipada da mulher lésbica, associada a uma imagem masculinizada e que, por consequência, não seria um alvo passível de sofrer assédio. Em contrapartida, apareceu a palavra "feminismo", que parece corroborar com essa perspectiva do estereótipo da lésbica vinculada ao masculino, relacionada à compreensão errada de que as feministas são contra os homens.

Ademais, é importante observar que, no caso das mulheres lésbicas, mesmo não aparecendo uma conotação específica voltada para o preconceito sofrido devido ao gênero, esse grupo pode sofrer um acúmulo de preconceitos, resultado da intersecção entre sexismo e lesbofobia. A partir disso, pensam-se como limitação do estudo e sugestão de pesquisas futuras, trabalhos que busquem analisar esse cruzamento entre outras diferentes minorias, que podem potencializar esse preconceito, como, por exemplo, mulheres negras, mulheres pobres, mulheres transexuais ou outras que fogem do padrão normativo.

Outro ponto que pode ser destacado como limitante do estudo consiste no fato da maioria dos participantes caracterizar-se como heterossexual $(95 \%)$ e mais da metade como mulher $(55 \%)$. Supõe-se que, se mais participantes da pesquisa fossem lésbicas, poderia haver uma maior variabilidade das evocações para esse grupo, inclusive com a apresentação de termos com sentido positivo, que sustentem a questão da participação da mulher no contexto de trabalho para além da exclusão. Diante disso, sugerem-se estudos futuros com o objetivo de avaliar essas representações sociais na perspectiva de mulheres lésbicas. 
Destarte, confia-se que os resultados alcançados pela presente pesquisa trazem uma compreensão sobre as representações sociais que os indivíduos têm em torno da mulher no contexto de trabalho. Ademais, não é possível falar de uma única forma de discriminação contra a mulher. Mulheres lésbicas detém uma representação diferente das mulheres heterossexuais, o que, por sua vez, leva a diferentes formas de preconceito e exclusão social. Portanto, espera-se que os resultados dessa pesquisa possam contribuir para a reflexão e promoção de políticas e ações afirmativas que combatam as diferentes formas de exclusão que as mulheres sofrem no contex to de trabalho.

\section{Referências}

Abric, J. C. (2001). Prácticas sociales y representaciones. México: Coyoacán.

Amaral, G. A. (2012). Os desafios da inserção da mulher no mercado de trabalho. Itinerarius Reflectionis, 8(2), 1-20. doi:10.5216/rir.v2i13.22336

Barreto, M., \& Ellemers, N. (2005). The burden of benevolent sexism: How it contributes to the maintenance of gender inequalities. European journal of social psychology, 35(5), 633-642. doi:10.1002/ejsp.270

Belo, R. P., \& Camino, L. (2012). Trabalho e gênero: Elaborações discursivas sobre os papéis profissionais. Cadernos de Psicologia Social do Trabalho, 15(2), 271-286. doi:10.11606/issn.1981-0490.v15i2p271-286

Camargo, B. V., \& Justo, A. M. (2013). IRAMUTEQ: Um software gratuito para análise de dados textuais. Temas em psicologia, 21(2), 513-518. doi:10.9788/TP2013.2-16

Carvalho, M. D. C. O. (2006). Os discursos das mulheres em posições de poder. Cadernos de Psicologia Social do Trabalho, 9(2), 57-72. doi:10.11606/issn.1981-0490.v9i2p57-72

Comissão Econômica para a América Latina e o Caribe. (2016). Observatório de igualdade de gênero da América Latina e do Caribe. New York: CEPAL. Recuperado de https://oig.cepal.org/pt

Cortez, M. B., \& Souza, L. (2008). Mulheres (in)subordinadas: O empoderamento feminino e suas repercussões nas ocorrências de violência conjugal. Psicologia: Teoria $e$ Pesquisa, 24(2), 171-180. doi:10.1590/S0102-37722008000200006

Dunne, G. (1997). Lesbian lifestyles: Women's work and the politics of sexuality. London: MacMillan. 
Fitzgerald, D. L. (1993). The last great open secret: The sexual harassment of women in the workplace and academia. Washington, DC: Federation of Behavioral, Psychological and Cognitive Sciences.

Freitas, M. E. D. (2001). Assédio moral e assédio sexual: Faces do poder perverso nas organizações. Revista de Administração de Empresas, 41(2), 8-19. doi:10.1590/S0034-75902001000200002

Garbin, A. D. C., \& Fischer, F. M. (2012). Assédio moral no trabalho e suas representações na mídia jornalística. Revista de Saúde Pública, 46(3), 417-424. doi:10.1590/S003489102012005000035

Garnets, L. (1996). Life as a lesbian: What does gender have to do with it? In J. C. Chrisler, C. Golden, \& P. D. Rozee (Eds.), Lectures on the psychology of women (pp. 137-151). New York: McGraw-Hill.

Glick, P., \& Fiske, S. (1996). The ambivalent sexism inventory: Differentiating hostile and benevolent sexism. Journal of Personality and Social Psychology, 70(3), 491-512. doi:10.1037/0022-3514.70.3.491

Glick, P., \& Fiske, S. (2011). Ambivalent sexism revisited. Psychology of women quarterly, 35(3), 530-535. doi:10.1177/0361684311414832

Gregus, S. J., Rummell, C. M., Rankin, T. J., \& Levant, R. F. (2014). Women's experiences of sexual attention: A cross-sectional study of US university students. International Journal of Sexual Health, 26(4), 239-257. doi:10.1080/19317611.2014.885922

Grupo Gay da Bahia. (2018). Relatório 2017 - Mortes LGBT no Brasil. Salvador: GGB. Recuperado de https://grupogaydabahia.com.br/2018/01/18/brasil-campeao-mundialde-crimes-lgbt-fobicos

Hirata, H. (2005). Globalização, trabalho e gênero. Revista de Políticas Públicas, 9(1), 111128. http://www.periodicoseletronicos.ufma.br/index.php/rppublica/article/view/3770/1848

Jordão, A. (2011). Igualdade no trabalho: Um desafio contínuo: Relatório Global no quadro do seguimento da Declaração sobre os Princípios e Direitos Fundamentais no Trabalho. Ex aequo, (24), 155-158. Recuperado de http://www.ilo.org/brasilia/publicacoes/WCMS_226726/lang--pt/index.htm

Kilianski, S. E., \& Rudman, L. A. (1998). Wanting it both ways: Do women approve of benevolent sexism? Sex roles, 39(5-6), 333-352. doi:10.1023/A:1018814924402 
Kite, M. E., \& Deaux, K. (1987). Gender belief systems: Homosexuality and the implicit inversion theory. Psychology of Women Quarterly, 11(1), 83-96. doi:10.1111/j.14716402.1987.tb00776.x

León, M. (2001). El empoderamiento de las mujeres: Encuentro del primer y tercer mundos en los estudios de género. Revista de estudios de género: La ventana, 2(13), 94-106. Recuperado de https://dialnet.unirioja.es/servlet/articulo?codigo=5202169

Leone, E. T., \& Teixeira, M. O. (2013). O avanço das mulheres na expansão do mercado de trabalho após 2003. Carta Social e do Trabalho, (29), 2-21. Recuperado de http://www.cesit.net.br/wp-content/uploads/2015/08/CartaSocial29.pdf

Lima, M. E. O. (2003). Normas sociais e racismo: Efeitos do individualismo meritocrático e do igualitarismo na infra-humanização dos negros (Tese de Doutorado). Instituto Universitário de Lisboa, Lisboa, Portugal.

Matos, M. I., \& Borelli, A. (2012). Espaço feminino no mercado de trabalho. In Pinsky, C. B., \& Pedro, J. M. (Orgs.), Nova história das mulheres no Brasil (pp. 126-147). São Paulo: Contexto.

Morris, J. F., Balsam, K. F., \& Rothblum, E. D. (2002). Lesbian and bisexual mothers and nonmothers: Demographics and the coming-out process. Journal of Family Psychology, 16(2), 144. doi:10.1037//0893-3200.16.2.144

Moscovici, S. (2017). Representações sociais: Investigações em psicologia social. Petrópolis: Vózes.

Neto, H. L. C., \& Bicalho, R. A. (2017). Violência simbólica, lesbofobia e trabalho: Um Estudo Em Juiz De Fora. HOLOS, 4, 249-265. Recuperado de http://www2.ifrn.edu.br/ojs/index.php/HOLOS/article/view/5871

Nogueira, M. C. O. C. (2006). Os discursos das mulheres em posições de poder. Cadernos de Psicologia Social do Trabalho, 9(2), 57-72. doi: 10.11606/issn.1981-0490.v9i2p57-72

Nunes, T. S., \& Tolfo, S. R. (2015). O assédio moral no contexto universitário: Uma discussão necessária. Revista de Ciências da administração, 17(41), 21-36. doi:10.5007/2175-8077.2015v17n41p21

Peplau, L. A., \& Fingerhut, A. (2004). The paradox of the lesbian worker. Journal of Social Issues, 60(4), 719-735. doi:10.1111/j.0022-4537.2004.00382.x

Petersen, C. (1994). Living Dangerously: Speaking Lesbian, Teaching Law. Canadian Journal of Women \& Law, 7(2), 318. Recuperado de http://connection.ebscohost.com/c/articles/11075543/living-dangerously-speakinglesbian-teaching-law 
Proni, T. T. W. R., \& Proni, M. W. (2018). Discriminação de gênero em grandes empresas no Brasil. Estudos Feministas, 26(1), 1-21. doi:10.1590/1806-9584.2018v26n141780

Ratinaud, P. (2009). Iramuteq: Interface de $R$ pour les analyses multidimensionnelles de textes et de questionnaires. Recuperado de http://www.iramuteq.org

Reis, S. S., \& Freitas, P. (2016). A inserção da mulher no mercado de trabalho e a ampliação da participação social no espaço público. Anais do Seminário nacional demandas sociais e políticas públicas na sociedade contemporânea. Universidade de Santa Cruz do Sul, Rio Grande do Sul, Brasil, 12. Recuperado de https://seminarionacional.eventize.com.br/index.php?pagina=12

Rich, A. (2010). Heterossexualidade compulsória e existência lésbica. Bagoas-Estudos gays: gêneros e sexualidades, 4(5), 17-44. Recuperado de https://periodicos.ufrn.br/bagoas/article/view/2309

Rosa, M., \& Quirino, R. (2017). Relações de gênero e ergonomia: Abordagem do trabalho da mulher operária. HOLOS, 5, 345-359. doi:10.15628/holos.2017.4772

Sá, C. P. (1996). Núcleo central das representações sociais. Rio de Janeiro: Vozes.

Salino, R. E. (2017). Mulheres e trabalho: Diversidade sexual e vivências profissionais e desenvolvimento (Dissertação de Mestrado). Universidade Federal do Paraná, Martinhos, PR, Brasil. Recuperado de https://acervodigital.ufpr.br/handle/1884/47335

Salino, R. E., Covolan, N. T., Pereira, P. P., \& Signorelli, M. C. (2018). Múltiplas faces das violências contra mulheres homossexuais e bissexuais no trabalho: Uma abordagem de pesquisa com métodos mistos. Revista Latino-Americana de Geografia e Gênero, 9(1), 177-194. doi:10.5212/Rlagg.v.9.i1.0010

Santos, L. C. D., Carvalho, A. B., Amaral, J. G., Borges, L. A., \& Mayorga, C. (2016). Gênero, feminismo e psicologia social no Brasil: Análise da revista Psicologia \& sociedade (1996-2010). Psicologia \& Sociedade, 28(3), 589-603. doi:10.1590/180703102016v28n3p589

Soares, G. S. \& Costa, J. C. (2011). Movimento lésbico e Movimento feminista no Brasil: Recuperando encontros e desencontros. Labrys - Estudos Feministas. Recuperado de http://www.labrys.net.br/labrys20/brasil/gilberta\%20jussara.htm

Swim, J. K., Ferguson, M. J., \& Hyers, L. L. (1999). Avoiding stigma by association: Subtle prejudice against lesbians in the form of social distancing. Basic and Applied Social Psychology, 21(1), 61-68. doi:10.1207/s15324834basp2101_6

Tajfel, H. (1982). Social psychology of intergroup relations. Annual review of psychology, 33(1), 1-39. doi:10.1146/annurev.ps.33.020182.000245 
Think Olga. (2019). O machismo também mora nos detalhes. Recuperado de http://thinkolga.com/2015/04/09/o-machismo-tambem-moranos-detalhes/

Torma, C. S. L. (2013). Lésbica no ambiente de trabalho: Análise dos efeitos de ser lésbica em organizações contemporâneas (Monografia de Bacharelado). Universidade de Brasília, Departamento de Administração, Brasília, DF, Brasil. Recuperado de https://bdm.unb.br/handle/10483/5249

Verniers, C., \& Vala, J. (2018). Justifying gender discrimination in the workplace: The mediating role of motherhood myths. PloSone, 13(1), e0190657. doi:10.1371/journal.pone.0190657

Wachelke, J., \& Wolter, R. (2011). Critérios de construção e relato da análise prototípica para representações sociais. Psicologia: Teoria e pesquisa, 27(4), 521-526. doi:10.1590/S0102-37722011000400017

World Economic Forum. (2017). The Global Gender Gap Report 2017. Recuperado de http://www3.weforum.org/docs/WEF_GGGR_2017.pdf

\section{Endereço para correspondência}

\section{Natalia Fernandes Teixeira Alves}

Avenida Visconde do Rio Branco, 3585. Fortaleza - CE, Brasil. CEP 60055-171

Endereço eletrônico: nataliafta_@hotmail.com

\section{Luciana Maria Maia}

Avenida Washington Soares, 1321 bloco N sala 13, Fortaleza - CE, Brasil. CEP 60811-905

Endereço eletrônico: lumariamaia@ @otmail.com

\section{Luiza Barbosa Porto Lima}

Avenida Odilon Guimarães, 4555, Fortaleza - CE, Brasil. CEP 60831-295

Endereço eletrônico: luizabpl@gmail.com

\section{Luana Elayne Cunha de Souza}

Avenida Washington Soares, 1321 bloco N sala 13, Fortaleza - CE, Brasil. CEP 60811-905

Endereço eletrônico: luana_elayne@ hotmail.com

\section{Iara Andrade de Oliveira}

Rua Francisco Farias Filho, 233, Fortaleza - CE, Brasil. CEP 60810-110

Endereço eletrônico: iara_andrade_@hotmail.com

\section{Ágatha Aila Amábili de Meneses Gomes}

Rua Ministro Petrônio Portela, 418, Fortaleza - CE, Brasil. CEP 60810-820

Endereço eletrônico: agatha.aila@ hotmail.com

Recebido em: 23/09/2019 
Natalia Fernandes Teixeira Alves, Luciana Maria Maia, Luiza Barbosa Porto Lima, Luana Elayne

Cunha de Souza, Iara Andrade de Oliveira, Ágatha Aila Amábili de Meneses Gomes

Reformulado em: 17/03/2020

Aceito em: 15/04/2020

\section{Notas}

* Doutoranda em Psicologia pela Universidade de Fortaleza (UNIFOR). Membro do Laboratório de Estudos sobre Processos de Exclusão Social (LEPES).

** Doutora em Psicologia Social pela Universidade Federal da Paraíba. Professora Titular da Universidade de Fortaleza (UNIFOR). Coordenadora do Laboratório de Estudos sobre Processos de Exclusão Social (LEPES).

*** Graduada pela Universidade de Fortaleza (UNIFOR). Mestranda pela Universidade Federal do Ceará (UFC). Integrante do Laboratório de Estudos dos Processos de Exclusão Social (LEPES).

**** Doutora em Psicologia Social pela Universidade Federal da Paraíba. Professora Adjunta da Universidade de Fortaleza (UNIFOR). Coordenadora do Laboratório de Estudos sobre Processos de Exclusão Social (LEPES) ***** Mestra em Psicologia pela Universidade de Fortaleza (UNIFOR). Integrante do Laboratório de Estudos sobre Processos de Exclusão Social (LEPES).

****** Doutoranda em Psicologia pela Universidade de Fortaleza (UNIFOR). Membro do Laboratório de Estudos sobre Processos de Exclusão Social (LEPES).

Financiamento: Projeto Universal - CNPq.

Este artigo de revista Estudos e Pesquisas em Psicologia é licenciado sob uma Licença Creative Commons Atribuição-Não Comercial 3.0 Não Adaptada. 